\title{
NOTAS
}

\section{La fragilidad del pensamiento después de Auschwitz}

\section{Pablo Pérez Espigares'}

Fecha de recepción: 13 de mayo de 2017

Fecha de admisión: 9 de junio de 2017.

La experiencia que supusieron los regímenes fascistas, sobre todo el nazismo, con la desembocadura de su dinámica totalitaria en la segunda guerra mundial y con la negatividad absoluta de sus campos de exterminio, escenarios del asesinato industrialmente organizado de millones de personas, destacando la llamada shoah en el que fueron masacrados seis millones de judíos, ha sido objeto de numerosas reflexiones por parte de filósofos, sociólogos, literatos e, incluso, de cineastas. Semejante atrocidad no es ajena a lo que ha ido fraguándose en la trayectoria histórica de occidente como proyecto civilizatorio, pero con ella se alcanza un punto sin retorno en el que la modernidad misma aparece cuestionada totalmente desde la barbarie que emerge como su reverso, de la misma manera que la llustración se ve desmentida en su contrario, por ella misma provocada. Al excluir que ese terrible acontecimiento sea un mero "accidente histórico", el análisis crítico se ve obligado a ir al fondo del devenir de un entramado histórico-cultural que da de sí semejantes aberraciones. Sin intentar reflejar aquí cómo dicha tarea ha sido afrontada desde diferentes ámbitos, lo que pretendemos a continuación es apuntar cómo ha afectado a la filosofía y a la teología posteriores lo acontecido en Auschwitz, sin perder de vista que dicha experiencia, por su desmesura, siempre permanece como algo inefable e inenarrable, corriendo el riesgo de traicionar la memoria de las víctimas aquéllos que intenten un acercamiento explicativo a la misma.

\footnotetext{
' Departamento de Humanidades y Filosofía. Universidad Loyola Andalucía.
} 
No obstante, antes de abordar el tema, y enlazando con esto último para intentar captar lo delicado de la cuestión, conviene aludir a los relatos desgarrados y sobrecogedores de algunos de los supervivientes de los campos de concentración, testimonios "quebrados", utilizando una expresión de J. Améry o M. Blanchot, que han pretendido que esas atrocidades no caigan en el olvido. Sin poder desprenderse de un pasado imborrable, los que consiguieron salir con vida de Auschwitz se encuentran "pillados" entre la ineludible prohibición de callar y la conciencia extremadamente lúcida de la imposibilidad de hablar, entre la necesidad moral de dar testimonio y el sentimiento de culpa por haber escapado a la aniquilación². Culpabilidad que en ocasiones deja traslucir hasta una especie de "vergüenza" ante la incapacidad de reflejar fielmente lo que suponía la vida en esos campos de exterminio, y ante el temor de traicionar con ello a los "auténticos" testigos de la catástrofe, aquellos que, totalmente aniquilados, habían sido silenciados para siempre ${ }^{3}$.

El mismo carácter traumático de la experiencia de los supervivientes, que por su violencia inusitada no puede presentarse totalmente a la conciencia, explica en parte la imposibilidad de ese testimonio necesario. Eso dificulta la comprensión, el control y la narración de dicha experiencia por parte de los testigos, que, al intentar comunicarla, más que alivio padecen una retraumatización insoportable que puede incluso hacerles sucumbir. Por otro lado, si bien es cierto que la plasmación en una narración de ese sufrimiento indescriptible posibilita su conocimiento individual y colectivo, también lo es que con ella se pervierte su esencial incomprensibilidad. En efecto, en la narración la memoria de Auschwitz acaba siendo integrada en una sucesión cronológica y un esquema temporal secuencial que no hace justicia a dicho acontecimiento, el cual, como trauma, constituye un pasado que se re-presenta constantemente, es decir, que siempre se presenta de nuevo y no puede ser borrado. Por eso

la lógica de la permanencia del trauma impide el alivio que concede el tiempo cronológico, que es el que hace posible el olvido. (... puesto que) toda narración conclusiva que niega el presente del horror se coloca del lado de los verdugos y no del lado del sufrimiento persistente a causa del pasado 4 .

2J. A. Zamora (2004) Th. W. Adorno: Pensar contra la barbarie, cap. 1: "Después de Auschwitz", 21-61.

${ }^{3}$ Sobre ello habla Primo Levi en la entrevista que aparece en el apéndice de 1976 a Si esto es un hombre.

${ }^{4}$ J. A. ZAMORA (2004) 30. 
En esa línea, lo difícil de ese tipo de testimonio puede captarse si atendemos a la incomprensibilidad de los hechos vividos y presenciados por las víctimas del "sistema concentracionario". La situación vivida en los campos de concentración debió ser algo que supera todo límite imaginable, de forma que aquí se cumpliría con creces el tópico de que la realidad supera a la ficción. Por mucho que intentemos entender nunca lo conseguiremos, ya que el abismo entre nuestro mundo "normal" y aquel horror es insalvable, dado que Auschwitz fue el intento fríamente calculado de reducir masivamente a los hombres a meros objetos carentes de humanidad, de los que se podía abusar y a los que se podía exterminar en cualquier momento. Ahora bien, la aniquilación es el punto final de un proceso que arranca con la discriminación excluyente y pasa por la deshumanización de las víctimas. En esas situaciones límite irrepresentables, la muerte era omnipresente. Se puede decir que "vivir" en Auschwitz era como esta muerto en vida, pues ésta ya no tiene otra lógica que la de la pura e inhumana lucha por la supervivencia. De ahí que los llamados "muselmann", aquellos que por ser más débiles e ineptos estaban destinados a la selección, puedan considerarse los "testigos integrales" de este cruel experimento 5 .

Quizás ahora se comprenda mejor el conflicto que experimentan muchos supervivientes entre la necesidad de ser escuchado y la imposibilidad de serlo de hecho: "es un temor a hacerse cómplices de una traición a los muertos y a su memoria bajo la apariencia de una comunicabilidad que ignora el abismo que la atraviesa y la frustra"b. El también pensador judío E. Wiesel insiste, por ello, en que el silencio ha de convertirse en el núcleo del testimonio, llegando a afirmar que él no ha escrito para que el lector lo conozca, sino para que sepa que jamás llegará a conocerlo. No se trata, claro está, de una complicidad con el silencio del verdugo, sino de hacer presente la interrupción del discurso para poner de manifiesto el sinsentido de tanta negatividad acumulada en Auschwitz. En ese sentido, es comprensible que los que lograron sobrevivir teman que, al ignorar el foso que separa los dos mundos, se produzca una comprensión precipitada por parte de los receptores de su testimonio, que de ese modo, podrían otorgarle un valor estético o funcional.

Efectivamente, para que la experiencia de Auschwitz salga a la luz, los testigos precisan de una "audiencia" responsable, de interlocutores capaces de asumir esa realidad testimoniada que no ha sido experimentada por ellos mismos y de participar así en la lucha de la víctima con sus recuerdos y con su pasado trau-

${ }^{5}$ Ibid., 27.

${ }^{6}$ Ibid., 28. 
mático. En este punto, han surgido cuestiones decisivas en torno a la catástrofe de Auschwitz, como pueden ser las relativas a los límites estéticos y morales de la representación artística de la "shoah" o la referida a la posibilidad de transmitir el verdadero significado de dicho acontecimiento a generaciones posteriores, pues alguien podría tener la tentación de buscar en testimonios parecidos un mensaje heroico o salvador, lo cual impediría una verdadera escucha del mensaje que porta y desvirtuaría la conciencia de la irreparabilidad de Auschwitz.

Según lo que dice Th. W. Adorno ${ }^{7}$, toda representación artística después de la catástrofe, incluidos los relatos autobiográficos de este tipo, se hallan en una encrucijada, en una situación paradójica que viene marcada por su responsabilidad en la memoria del sufrimiento y, al mismo tiempo, por la prohibición de la estetización del mismo, algo casi inevitable desde el momento en que el sufrimiento real se convierte en imagen o, como ya hemos dicho, se plasma en una narración. Adorno nos hace ver la aporía sobre la que se sostienen las representaciones de Auschwitz, pues al intento de mostrar su sinsentido le acompaña siempre la donación de sentido que es inherente a la forma estética. Está criticando así lo inadmisible de integrar la barbarie de dicho proceso convirtiéndola en materia de producción estética y, yendo más lejos, está denunciando el intento de restablecer sin más el proceso cultural sin tomar conciencia de la fractura que supuso la susodicha catástrofe. Ni que decir tiene que obras como la de Primo Levi no habrían caído en ese error, ya que implícitamente han logrado mostrar la irrepresentabilidad de la shoah, pero no se puede decir lo mismo de otras producciones, como pueden ser determinadas películas hollywoodienses, que hacen de dicho acontecimiento un producto del mercado asimilado por la industria cultural.

Tras lo dicho, cabe señalar que la reflexión de Adorno en torno al arte después de Auschwitz apunta no tanto al sinsentido de los campos como al sinsentido de las estructuras sociales y culturales que los posibilitaron. Lo que intentaba tematizar era, pues, la dialéctica entre cultura y barbarie, lo que él y Horkheimer habían denominado dialéctica de la llustración, esto es, la esencial interrelación entre progreso y regresión, la complicidad entre la razón estratégico-instrumental de la modernidad y el principio de dominación. Desde el horizonte que marca esta reflexión, podemos entender la radicalidad de la pregunta de Adorno sobre si es posible seguir haciendo filosofía-y teología- después de Auschwitz. No cabe duda de que tanto la teología judeo-cristiana como el legado de la llustración quedan arrinconados a partir de este genocidio sin precedentes, ya que tanto la

${ }^{7}$ Th. W. ADORNO (1992). 
afirmación de que Dios es providente y se preocupa de los suyos en los acontecimientos históricos, como la de que el progreso lleva a la emancipación humana, se ven ahora fuertemente cuestionadas 8 . Nos ocuparemos en primer lugar de esta última cuestión, intentando ver, también de la mano de Adorno, cuál es la respuesta filosófica viable. Posteriormente, nos centraremos en las repercusiones sobre la reflexión teológica.

Auschwitz marca, sin duda, un antes y un después en la historia de la humanidad, constituye lo que se dice la "quiebra de la civilización"9. La aniquilación indiscriminada de seres humanos de modo industrial es algo inaudito que va más allá de toda lógica y que escapa a lo concebible. Somos incapaces de comprender el exterminio judío, pues se trata, como diría Finkielkraut, de un "crimen gratuito", que no responde a necesidad militar alguna ni tampoco se ajusta a elementos de la racionalidad económica o política ${ }^{10}$. Por más que el asesinato y la aniquilación de vidas humanas sea siempre y sin excepción algo deleznable y sin justificación, conviene subrayar la singularidad e inconmensurabilidad de lo ocurrido en Auschwitz con respecto al resto de la historia, sin caer en la trampa de intentar concebirlo como un incidente más o como una especie de invariante histórica afectada sólo por importantes diferencias de grado. La afirmación de la pura invariabilidad supondría "bagatelizar" todas las catástrofes haciéndolas intercambiables, y llevaría a una resignación frente a lo inevitable, al mismo tiempo que se cometería una grave injusticia contra las víctimas al eliminar las diferencias entre ellas $^{11}$. Sin embargo, la afirmación de su singularidad no debe llevarnos tampoco a reducir el acontecimiento en cuestión a algo puramente contingente, ya que eso supondría una relativización minimizadora de la relevancia de Auschwitz. Hay que tener presentes, entonces, los rasgos estructurales y las condiciones sociales que lo han propiciado.

Por tanto, si bien es cierto que la búsqueda de una racionalidad económica, demográfica o ideológica para explicar el genocidio puede suponer una cierta racionalización $y$, con ello, una justificación del mismo, el rechazo de cualquier vínculo entre las "racionalidades dominantes" en el proceso de modernización y

8 J. A. Estrada (2001) cap. 6: "Creer en Dios después de Auschwitz y Hiroshima", 153-179.

9 J. A. ZAMORA (2004) 43 ss.

${ }^{10}$ A. Finkielkraut(1990) 19.

11 J. A. ZAMORA (2004) 44. 
el crimen nos dejaría, por otra parte, sumidos en un vacío interpretativo que anularía toda nuestra crítica. En este sentido, es necesario captar la dialéctica entre la quiebra civilizatoria que es Auschwitz y el continuo social que lo hizo posible, sin caer, por otra parte, en la miopía de la determinación causal determinista ${ }^{12}$. Para ello, no obstante, hay que superar, de nuevo en la línea de Adorno, el "principio de identidad" imperante en el pensamiento occidental, que no percibe la singularidad cualitativa ni la negatividad extremas inherentes a Auschwitz y no capta la identidad paradójica dentro del proceso que ha hecho posibles esos horrores inimaginables ${ }^{13}$.

Auschwitz, por tanto, acaba con el optimismo que escondía las contradicciones del proceso emancipador moderno y termina por desvelar que la barbarie no es sólo lo otro de la modernidad, sino que es algo que pertenece a su mismo núcleo. Los campos de concentración, y también la invención de la bomba atómica y sus posteriores consecuencias genocidas en Hiroshima, son también resultado de la racionalidad instrumental, calculadora y eficiente de la que se regodea la modernidad occidental:

la razón científico-técnica se convierte en cínica cuando no se deja afectar por exigencias éticas, sentimientos de compasión y solidaridad, e intereses humanistas que desbordan el marco del interés propio ${ }^{14}$.

De ahí el nuevo imperativo categórico que, según Adorno, consciente de la persistencia de las condiciones que los hicieron posibles, ha de regir nuestras acciones y pensamientos: "que no se repita Auschwitz"15.

${ }^{12}$ M. R. MATE (2003) 11.

${ }^{13}$ A todo esto que venimos diciendo se refiere brevemente Primo Levi en la mencionada entrevista: Debo admitir que prefiero la humildad con que algunos historiadores entre los más serios (...) confiesan no comprender el antisemitismo furibundo de Hitler y, detrás de él, de Alemania. Quizás no se pueda comprender todo lo que sucedió, o no se deba comprender, porque comprender es casi justificar (...) En el odio nazi no hay racionalidad (...) No podemos comprenderlo; pero podemos y debemos comprender dónde nace, y estar en guardia. Si comprender es imposible, conocer es necesario, porque lo sucedido puede volver a suceder, las conciencias pueden ser seducidas y obnubiladas de nuevo: las nuestras también, cfr. P. LEVI (1995) 208.

14 J. A. Estrada, op. cit., 166.

${ }^{15}$ Algo parecido expresa Primo Levi cuando dice que "si desde el interior del campo algún mensaje hubiese podido dirigirse a los hombres libres habría sido éste: no hagáis nunca lo que nos están haciendo aquí", op. cit., 58. 
Adorno, por tanto, desde su insistencia en la negatividad de lo existente y en el horror y el sufrimiento que se perpetúa en la historia, nos exhorta a un cambio de perspectiva en la consideración de la misma, desde el que seamos capaces de pensar conjuntamente continuidad y discontinuidad, identidad y no-identidad, para así romper su lógica de dominio y acabar con el continuum de injusticia sobre el que se asienta. Lo que exige, con otras palabras, es adoptar, en honor a la verdad de la historia, la perspectiva de sus víctimas, la de los oprimidos, para los cuales todo progreso es nulo y el sufrimiento, lejos de ser la excepción, es la regla de sus vidas $^{16}$. Se trata, entonces, como también sostiene W. Benjamin, de recordar las catástrofes pasadas, de volverse hacia las posibilidades frustradas de humanidad para tomar conciencia de la realidad presente en medio de la vorágine del proceso histórico. Sólo desde el recuerdo solidario con las víctimas y desde la memoria de las esperanzas incumplidas se puede proceder a una crítica de las catástrofes del presente. Podemos afirmar, por tanto, que el imperativo de Adorno se hace en nuestra actualidad de guerra y terrorismo, de hambrunas y empobrecimiento, de devastación ecológica, más necesario que nunca.

Así pues, Auschwitz no fue una excepción posibilitada sólo por un vacío ético y religioso, sino que detrás hay una ética y una religiosidad, y, sobre todo, una racionalidad institucional y social, y una determinada teología y eclesiología que fueron compatibles e incluso colaboradoras con la gestación de ese acontecimiento. No sólo una forma de hacer filosofía, sino también loa concepción teológica tradicional ha sido globalmente cuestionada por Auschwitz, de donde surge una pregunta radical respecto de la fe en un Dios creador y en un padre y señor de la historia, tal y como se concibe en la tradición judeo-cristiana. El interrogante afecta, por un lado, a la elección y promesa divinas, es decir, a la vieja fe hebrea basada en el Dios del éxodo, que elige y libera al pueblo de la esclavitud, y en el Dios de los padres, que promete una tierra a un pueblo nómada. Auschwitz aparece como el final de una visión triunfalista de la historia y arroja sus sombras sobre la paternidad providencial de Dios, que deja perecer a sus hijos, y sobre la misma idea de redención de la historia, que es el núcleo de la escatología judeo-cristiana frente a la simple teología del más alláp ${ }^{77}$.

Efectivamente, ya no es posible desarrollar cristologías triunfales, ni afirmar que vivimos en una era mesiánica. La shoah se opone a una teología burguesa o

$16 \mathrm{J.}$ A. ZAMORA (2004) $46 \mathrm{ss}$.

17 J. A. EsTRADA (2001) 162. A este respecto dice Primo Levi: hoy pienso que, sólo por el hecho de haber existido Auschwitz, nadie debería hablar en nuestros días de Providencia, op. cit., 165. 
complaciente, que no toma en serio el dolor humano y la interpelación que surge de ahí ante una redención prometida, siempre esperada y que nunca llega. En la misma línea, hay que rechazar cualquier teología de la retribución, que implica de algún modo una justificación del horror de los campos de concentración como justo castigo divino por el pecado colectivo de un pueblo. Esto es lo que se ha mantenido en la tradición cristiana al sostener hasta el siglo XX la idea del "pueblo réprobo", justificando así, indirectamente, el silencio insoportable de tantos cristianos ante el exterminio judío.

Muchas cristologías, por otra parte, han preparado el camino a la shoah al europeizar a Jesús, esto es, al desjudaizarlo y arrancarlo de su tradición hebrea:

la negativización del judío, olvidando que el cristianismo surge como una rama suya, y la aplicación al cristianismo del título de "pueblo de Dios", ignorando que es la prerrogativa esencial de Israel (denigrado como pueblo deicida), es la que facilitó el exterminio del pueblo (...) El antisemitismo tiene como cómplice a la teología cristiana y su huella perdura hasta nuestros días ${ }^{18}$.

La teología cristiana más ramplona, que hace de Jesús maestro de la obediencia sin más, olvidando que la obediencia a Dios pasa por el discernimiento desde el sufrimiento humano, y que éste llevó a Jesús a desobedecer a las autoridades de su religión, se convierte en un cómplice ideológico del mal.

Por eso, Auschwitz constituye la gran advertencia sobre las consecuencias negativas de una fe en Dios contrapuesta a la sacralidad del hombre. Lo que nos enseña es que cualquier atentado contra el hombre es un deicidio y supone la pérdida de la inocencia. Auschwitz pone de manifiesto que el problema no es religión o increencia, pues ante semejante catástrofe eso pasa a un segundo plano, sino que lo importante es en apostar por la solidaridad, la compasión y la misericordia, se crea en Dios o no ${ }^{19}$. Éstas son las claves últimas para asumir el sinsentido de la historia desde la vinculación y la unilateral opción por las víctimas y los oprimidos de la historia, ya que sólo así se puede combatir la neutralidad y la indiferencia, y se puede recuperar la memoria del pasado como impedimento para legitimar nuevas agresiones.

\footnotetext{
18 J. A. EstradA, op.cit., 174.

19 Ibid., 172.
} 


\section{Bibliografía}

Adorno, Th.W. (1992) Dialéctica negativa (Frankfurt, 1966), Madrid, Taurus.

EstRadA, J.A. (2001) Razones y sinrazones de la creencia religiosa, Madrid, Trotta.

LEVI, P. (1995) Si esto es un hombre (Turín, 1947), Barcelona, Muchnik.

FINKIELKRAUT, A. (1990) La memoria vana: del crimen contra la humanidad, Barcelona, Anagrama.

Mate, M. R. (2003) Memoria de Auschwitz. Actualidad moral y política, Madrid, Trotta.

Zamora, J. A. (2004) Th. W. Adorno: Pensar contra la barbarie, Madrid, Trotta.

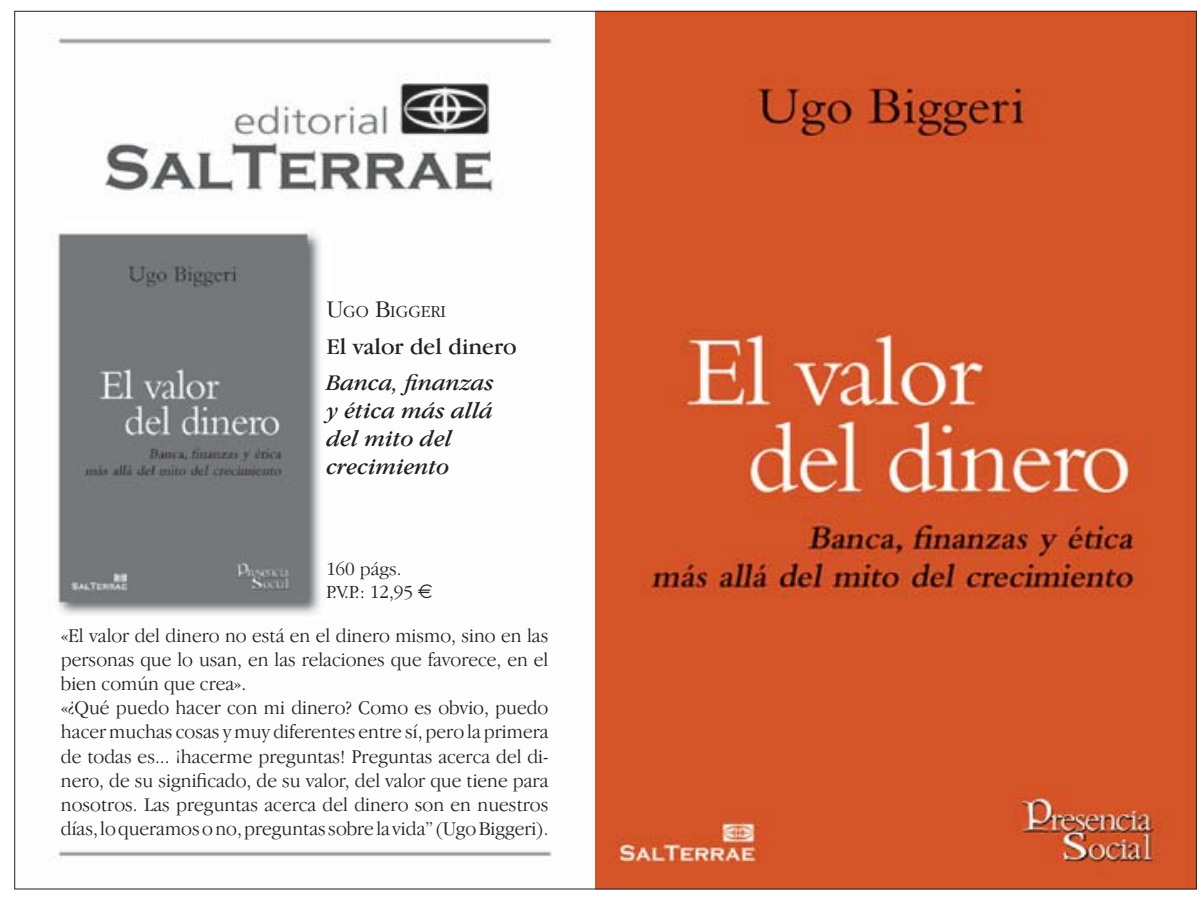

Revista de Fomento Social 72/2 (2017) 